\title{
SEXUAL HARASSMENT IN THE WORKPLACE. A PRACTITIONER'S REFLECTIONS ON THE CURRENT REVIEWS IN THE UNITED KINGDOM POST \#METOO
}

\author{
ACOSO SEXUAL EN EL ENTORNO LABORAL. LAS REFLEXIONES DE UN \\ ABOGADO EJERCIENTE SOBRE EL DEBATE ACTUAL EN EL REINO UNIDO \\ TRAS \#METOO
}

SHELAGH MCKENZIE

Solicitor registered with the Law Society of Scotland

Visiting Lecturer at Malaga University

smck@uma.es

\begin{abstract}
:
In autumn 2017 allegations about sexual harassment in the entertainment industry began to be reported in the press. ${ }^{1}$ These allegations lead to women in a wide range of industries speaking out about sexual harassment in their workplaces. The \#MeToo movement, together with the Everyday Sexism Project, have successfully highlighted the extent to which sexism, sexist comments and sexist behaviours continue to exist in our society today. ${ }^{2}$ As a consequence, in 2018 two key reports were published into sexual harassment in the workplace in the UK, and there has been a lot of discussion about whether we should strengthen or change the existing employment laws. ${ }^{3}$ This article outlines some of the current debates in the UK with a view to contributing to the debate in Spain. It also offers some reflexions on how preventative sexual harassment training could be tailored and adapted to address the reality of different roles/remits within an organisation.
\end{abstract}

Key words: Sexual harassment, training, managers, trade union representatives, human resources professionals, male and female colleagues, role of regulators, role of lawyers, confidentiality and non-disclosure agreements.

\section{Resumen:}

En otoño de 2.017 empezaron a aparecer en prensa denuncias sobre acoso sexual en la industria del entretenimiento. Dichas denuncias llevaron a otras mujeres de otras industrias a hablar sobre acoso sexual en sus lugares de trabajo. El movimiento \#MeToo, junto con el Proyecto "Everyday Sexism", han conseguido poner de relieve hasta qué punto el sexismo, los comentarios y comportamientos sexistas continúan existiendo a día de hoy en nuestra sociedad. Como consecuencia, en 2018 se publicaron dos informes clave sobre el acoso sexual en el entorno laboral en el Reino Unido, y se han generado numerosos debates sobre si se deberían reforzar o cambiar las leyes laborales. Este artículo resume algunos de los debates que se están produciendo

\footnotetext{
1 See, for example: https:/www.theguardian.com/film/2017/oct/13/harvey-weinstein-allegationshollywood-enablers

2 https://everydaysexism.com and https://witter.com/hashtag/metoo

${ }^{3}$ Section 26(2) of the Equality Act 2010.

REJIE Nueva época: Revista Jurídica de Investigación e Innovación Educativa Núm.19, Enero 2019, pp. 69-85

[En línea] http://www.revistas.uma.es/index.php/rejie

Recibido: octubre 2018

Aceptado: diciembre 2018
} 
actualmente en el Reino Unido, con el objetivo de contribuir al debate en España. Igualmente, ofrece algunas reflexiones sobre cómo se puede modelar la formación preventiva en acoso sexual y adaptarla a diferentes roles dentro de una organización.

Palabras clave: acoso sexual, formación, prevención, directores, representantes de los trabajadores, profesionales de recursos humanos, formación por género, papel de los reguladores, papel de los abogados, acuerdos confidenciales.

Summary: 1. Introduction. 1.1. The recent reviews of sexual harassment in the workplace in the UK. 1.2. The definition of sexual harassment. 1.3 How common is sexual harassment in the workplace? 1.4. Sexual harassment in the workplace is a business problem. 2. Proposed UK statutory code of practice on sexual harassment in the workplace. 3. Training and awareness raising for future employers and employees. 3.1. Training for senior managers on sexual harassment. 3.2. Training for human resources professionals. 3.3. Sexual harassment and awareness training for trade union and employee representatives. 3.4. Sexual harassment and awareness training specifically for male colleagues? 3.5. Sexual harassment and awareness training specifically for female colleagues? 4. The role of regulators and professional associations/organisations in ensuring that leaders are equipped to lead on sexual harassment. 5. The role of lawyers in drafting non-disclosure or confidentiality agreements. 6. Conclusions. Bibliography.

\section{Introduction.}

Sexual harassment is not only in the media news stories, but it is also firmly on the international legal agenda. The UK and Spain have signed up to the Sustainable Development Goals which require the elimination of all forms of discrimination against women by $2030 .{ }^{4}$ Article 40 of the Istanbul Convention, ${ }^{5}$ which Spain has already ratified and which the UK intends to ratify, deals specifically with sexual harassment and requires parties to take the "necessary legislative or other measures" to tackle sexual harassment.

In March 2018 there was a report published entitled Bullying and sexual harassment at the workplace, in public spaces and political life in the EU (hereinafter referred to as the "EU report"). ${ }^{6}$ The European Parliament has recently called on Member States to introduce measures to prevent and combat violence and harassment at the workplace including "comprehensive information and training courses to ensure that workers understand policies and procedures, and support for companies to draw up action plans to implement all these measures."7

\footnotetext{
${ }^{4}$ UN, Sustainable Development Goal 5.

${ }^{5}$ Council of Europe Convention on preventing and combating violence against women and domestic violence, Istanbul, 11.V.2011.

${ }^{6}$ European Parliament's Committee on Women's Rights and Gender Equality and published by the Policy Department for Citizen's Rights and Constitutional Affairs, March 2018, Bullying and sexual harassment at the workplace, in public spaces and political life in the EU (hereinafter the "EU report").

${ }^{7}$ European Parliament resolution of 11 September 2018 on measures to prevent and combat mobbing and sexual harassment at workplace, in public spaces, and political life in the EU (2018/2055(INI)).
} 


\subsection{The recent reviews of sexual harassment in the workplace in the UK.}

In March 2018, the Equality and Human Rights Commission in the United Kingdom, published a report entitled: Turning the tables: ending sexual harassment at work (hereinafter referred to as "the EHRC report"). ${ }^{8}$ This publication shared evidence about sexual harassment in the workplace gathered from around 1000 individuals and employers, and made a series of recommendations about how to end sexual harassment at work.

This was followed on 25 July 2018 by the review and publication on Sexual harassment in the workplace by the Women and Equalities Committee of the House of Commons (hereinafter referred to as "the WEC report") which endorsed some of the recommendations of the EHRC and made its own additional proposals. ${ }^{9}$ After hearing evidence from a wide range of interested parties, the Committee concluded that more preventative measures needed to be taken:

It is shameful that unwanted sexual behaviours such as sexual comments, touching, groping and assault are seen as an everyday occurrence and part of the culture in workplaces...There is considerable focus on protecting people's personal data and preventing money laundering, with stringent requirements on employers and businesses to meet their responsibilities in these areas. They should now put the same emphasis on tackling sexual harassment. ${ }^{10}$

\subsection{The definition of sexual harassment.}

Currently, the broad legal definition and concept of sexual harassment in both Spain and the UK is derived from European directives such as Directive 2006/54/EC on the implementation of the principle of equal opportunities and equal treatment of men and women in matters of employment and occupation (recast). ${ }^{11}$

The European civil law concept of sexual harassment has been transposed into the law in the UK and is "unwanted conduct of a sexual nature, which is intended to, or has the effect of, violating a person's dignity or creating an intimidating, hostile, degrading, humiliating or offensive environment for them."12 Unwanted conduct may be verbal, non-verbal or physical conduct of a sexual nature. ${ }^{13}$ Whether or not unwanted sexual conduct violates a person's dignity or creates an offensive environment depends on the victim's perspective and whether their reaction is reasonable in all the circumstances. ${ }^{14}$

\footnotetext{
${ }^{8}$ Equality and Human Rights Commission of the UK, March 2018, Turning the tables: Ending sexual harassment at work (hereinafter referred to as the" EHRC report").

${ }^{9}$ House of Commons Women and Equalities Committee Fifth Report of Session 2017-2019, July 2018, Sexual harassment in the workplace (hereinafter referred to as the "WEC report").

${ }^{10}$ Page 3 of the WEC report.

${ }^{11}$ Article 1(d) of Directive 2006/54/EC of the European Parliament and of the Council of 5 July 2006.

${ }^{12}$ Article 1(d) of Directive 2006/54/EC and Section 26 of the Equality Act 2010.

${ }^{13} \mathrm{Ibid}$.

${ }^{14}$ Section 26(4) of the Equality Act.
} 
In practice, the concept of what behaviours constitute "harassment" and "sexual harassment" can vary from country to country. ${ }^{15}$ In the UK, for example, a one-off incident can constitute harassment. ${ }^{16}$ The courts have held that unwanted sexual conduct does not need to be aimed at the complainant; there simply needs to be proximity. ${ }^{17}$ Further, the fact that a claimant has put up with the conduct for years, or joined in with "banter", does not necessarily mean that the conduct is not "unwanted." 18 In theory, a harassment claim can be brought by a colleague who does not share the "protected characteristic."19

Everyday examples of sexual harassment include:

- Hearing comments of a sexual nature being made about other women in the workplace.

- Displays of pornographic material.

- The circulation of pornography by email, messages etc.

- Being the subject of unwelcome jokes of a sexual nature.

- Having comments of a sexual nature made about their body or clothes.

- Unwanted touching such as a hand on the knee or lower back.

- Unwanted sexual advances.

- Requests or demands for sexual favours.

The trade unions in the UK have noted that social media and email are also increasingly involved in workplace sexual harassment. ${ }^{20}$

The objective of any sexual harassment awareness training should be to ensure that employees understand that sexual harassment as defined in this directive encompasses a whole range of behaviours or conduct on a sliding scale from the least serious examples such as "unwanted sexual jokes" to the most serious assaults which may also fall within criminal definitions of sexual harassment, assault or rape. ${ }^{21}$ Case law examples both from home and from other European countries are instructive on how this European concept is interpreted in practice across the European Union. ${ }^{22}$

\subsection{How common is sexual harassment in the workplace?}

As the EU report notes: "measuring the extent of sexual harassment is complicated by the fact that perceptions of sexual harassment vary from person to person, from country to country, and over time.",23

\footnotetext{
${ }^{15}$ An analysis of the different judicial interpretations in Spain and in the UK is beyond the scope of this article but will be the topic of a future article.

${ }^{16}$ Reed $v$ Stedman [1999] IRLR 299 (EAT).

${ }^{17}$ Moonsar v Fiveways Express Transport Ltd UKEAT/0476/04

${ }^{18}$ See, for example: Munchkins Restaurant Ltd and another $v$ Karmazyn and others UKEAT/0359/09

${ }^{19}$ Noble $v$ Sidhil Ltd UKEAT/0375/14/DA (note this was not a case specifically about sexual harassment)

${ }^{20}$ Trades Union Congress, 2016, Still just a bit of banter: sexual harassment in the workplace at page 7 (hereinafter referred to as the "TUC report").

${ }^{21}$ A consideration of the criminal law definitions of sexual harassment is out of the scope of this work.

${ }^{22}$ See page 48 of the EU report for more information on how different EU countries approach this issue.

${ }^{23}$ As noted on page 20 of the EU report.
} 
The UK Government does not currently collect data on the extent of sexual harassment in the workplace. ${ }^{24}$ Data from employment tribunals also does not enable cases involving allegations of sexual harassment to be quickly identified. For these reasons the WEC has recommended that the Government should collect data on the number of employment tribunal claims relating to sexual harassment allegations and commission surveys every three years to "determine the prevalence and nature of sexual harassment in the workplace." 25 The WEC recommends that the findings of each survey should be accompanied by "an evaluation of measures taken in the preceding period to tackle sexual harassment, and an action plan responding to the findings.",26

Notwithstanding this, various surveys and investigations exist which suggest that there is a high incidence of sexual harassment in the workplace although it is not regularly reported to employers. ${ }^{27}$ For example, between December 2017 and February 2018, the EHRC gathered evidence from around 1,000 individuals and employers. The EHRC also received 750 responses to an online survey: $75 \%$ of people who responded to the survey had experienced sexual harassment at work. The rest had witnessed harassment or supported others. ${ }^{28}$ Nearly all of the people who had been sexually harassed were women. ${ }^{29}$ Similarly, a BBC survey in November 2017 (surveying 6,206 adults in Great Britain) found that 40 per cent of women and 18 per cent of men ( 29 per cent overall) had experienced some form of unwanted sexual behaviour in the workplace in the preceding year. ${ }^{30}$

When the Trade Unions Congress reviewed the issue of sexual harassment in 2016 it found that specific groups are "disproportionately affected or susceptible to sexual harassment at work, such as young women between the ages of 18 and 24, employees with a disability or long-term illness, and members of sexual minority groups. Workers with irregular, flexible or precarious employment contracts, common in the services sector, and freelancers are more likely to experience sexual harassment." ${ }^{\text {31 }}$ Similarly, the EU Agency for Fundamental Rights has also noted that women with "irregular or precarious employment contracts, which are common for many jobs in the services sector, are also more susceptible to sexual harassment.",32

In Spain, there has also been a problem of visibility in terms of trying to assess the scale of the issue of sexual harassment, although the number of complaints dealt with by the Labour Inspectors are counted. It has been reported that the Observatory on Gender Violence is going to start to count the number of claims for sexual harassment. ${ }^{33}$ Although complaints to the labour inspectors are counted, it is submitted that sexual

\footnotetext{
${ }^{24}$ Paragraph 7 of the WEC report.

${ }^{25}$ Paragraph 140 of the WEC report.

26 Ibid.

${ }^{27}$ Paragraph 7 of the WEC report.

${ }^{28}$ Page 3 of the ECHR report.

${ }^{29}$ Ibid.

${ }^{30}$ As reported in Paragraph 9 of the WEC report: BBC - Sexual harassment in the work place 2017, survey by ComRes, November 2017.

${ }^{31}$ Paragraph 9 of the TUC report.

${ }^{32}$ Page 9 of the TUC report and EU Agency for Fundamental Rights (2014) Violence Against Women: An EU wide survey.

${ }^{33}$ Blanco, S, 6 March 2018, "Una de cada tres españolas se ha sentido acosada sexualmente”, El País.
} 
harassment claims raised at the pre-litigation stage and settled before the Spanish Mediation, Arbitration and Conciliation Service should also be declared and counted.

\subsection{Sexual harassment in the workplace is a business problem.}

Both in Spain and in the UK, employers can be vicariously liable for acts of sexual harassment (although in the UK there is a defence if the employer can show that they have taken all reasonable steps to prevent such harassment from occurring in which case only the employee is personally liable to pay any compensation). ${ }^{34}$ Notwithstanding this, the WEC report concluded that employers have "failed to tackle workplace sexual harassment, despite evidence that this is a long-standing and endemic problem." 35 Harassment can have a "devastating impact" on those who are subjected to it. ${ }^{36}$ The WEC heard evidence that: "mental and physical health often suffer, leading to anxiety, poor sleep, depression, loss of appetite, headaches, exhaustion or nausea. Victims feel humiliation, mistrust, anger, fear and sadness."37

As the WEC report highlights, aside from the ethical or moral reasons for tackling sexual harassment it is important not to lose sight of the business reasons: "a poor organisational culture and failure to deal with sexual harassment allegations lead to employees being dissatisfied with work, having a low opinion of their managers, absenting themselves or wanting to leave." which a business chooses to accept or reject, in terms of tolerating or not sexual "jokes" or comments about appearance or "minor" sexual related annoyances contributes to the culture within which the more serious forms of sexual harassment can thrive. Businesses must understand that the message from studies of employees who have suffered these types of regular transgressions is that this type of workplace culture undermines and belittles them. ${ }^{39}$ It takes true courage and leadership to eliminate sexual harassment in the workplace through transforming workplace cultures and promoting zero tolerance.

\section{Proposed UK statutory code of practice on sexual harassment.}

Both the WEC and the EHRC have recommended that employers in the UK should be placed under a "mandatory duty" to protect their workers from harassment and victimisation. The WEC has suggested that the code of practice to support the mandatory duty on employers to protect workers from harassment should set out good practice guidance on issues including:

\footnotetext{
${ }^{34}$ Section 109 of the Equality Act 2010 Article 8.13 of the Royal Legislative Decree 5/2000, 4 August, Breaches and Penalities of the Social Order (hereinafter referred to as "LISOS"which is the Spanish acronym for this piece of legislation).

${ }^{35}$ Paragraph 17 of the WEC report.

${ }^{36}$ Paragraph 12 of the WEC report.

37 Ibid.

38 Paragraph 13 of the WEC report which refers to Written Submissions from Chartered Institute of Personnel and Development and Dr. Afroditi Pina.

${ }^{39}$ Paragraph 12 of the WEC report.
} 
a) reporting systems and procedures and what employers should provide as a minimum, including guidance on anonymous reporting and any relevant data protection issues that arise;

b) support for victims, including access to specialist support and steps that should be taken to prevent victimisation of complainants;

c) how to investigate and record complaints, including a presumption that all complaints should be investigated unless there is a compelling reason not to;

d) how to identify when sexual harassment allegations may include criminal offences and how to conduct any investigation in a manner which does not prejudice any potential police investigation and criminal prosecution;

e) training, induction, risk assessments and other policies and practices; and

f) alternative dispute resolution including mediation, and risk assessments. ${ }^{40}$

The EHRC has suggested that the code of practice could be referred to in any sexual harassment litigation when determining whether the mandatory duty has been breached. $^{41}$ It is hoped that this code would change the way employers handle complaints of harassment, and in turn lead to increased reporting of such incidents.

If there was a mandatory duty to investigate and record any allegations of sexual harassment, perhaps this would deter otherwise serial harassers. It is also hoped that it would encourage complainants to speak out if they knew that their complaints could not be ignored. It has been argued that: "if a complainant is aware they are contributing to a portfolio of someone's behaviour, this may encourage complainants to speak out as there is a greater good they are doing."

A more controversial question which follows is whether previous complaints against the same alleged harasser which have been dismissed or not upheld should be included within subsequent investigations (particularly if there were no witnesses to either incident) $?^{43}$ There may be circumstances where an employer is entitled to exclude this information because of the nature of the previous incidents, the people involved, and the time that has elapsed between incidents (real or alleged), ${ }^{44}$ but it is worth considering whether this should be the general rule if the objective of the rule is to protect employees from serial harassers in the workplace?

In the UK there is no equivalent law to the Spanish rules on prescription for very serious breaches of employment law. ${ }^{45}$ Perhaps rules of prescription should not apply to sexual harassment or should be extended in order that, for example, a ten-year period rather than a six-month period could be considered.

\footnotetext{
${ }^{40}$ Paragraph 77 of the WEC report.

${ }^{41}$ Paragraph 1.2 of the ECHR report.

${ }^{42}$ Daurka K, March 2018, "Kiran Daurka of Leigh Day responds to Stephen Levinson", Employment Lawyers Association Briefing.

${ }^{43}$ Daurka K, January/February 2018, "Sexual harassment: Why we need a mandatory duty and inferences of fact", Employment Lawyers Association Briefing.

${ }^{44}$ Levinson S, "Sexual harassment: the debate continues", March 2018, Employment Lawyers Association Briefing.

${ }^{45}$ Article 60 of the Spanish Workers' Statute (Real Decreto Legislativo 2/2015, de 23 de octubre, por el que se aprueba el Texto Refundido de la Ley del Estatuto de los Trabajadores).
} 


\section{Training and awareness raising for future employees and employers.}

In Spain $39.9 \%$ of people employed work in micro businesses. ${ }^{46}$ If discrimination laws and rights including the right not suffer sexual harassment are to be effective, they must not only be given effect to in practice to those employees who work in businesses who employ over 250 employees, but also to employees who work in micro or small businesses (particularly if there exists no collective agreement with express obligations). It is worth considering whether educational establishments should have a more formal role in preparing young people, as future employees, for the workplace by providing sexual harassment and diversity training as an obligatory part of their curriculum?

Sexual harassment in the workplace is an extension of sexual harassment in society in general. Earlier this year, it was reported that Exeter University in the United Kingdom expelled some law students who had participated in exchanging sexist and racist WhatsApp messages. ${ }^{47}$ It can be deduced that these students simply did not realise how their "private jokes" could be interpreted by other students, teachers at the university, and the wider world beyond university. Schools, universities and further education providers are uniquely placed to try to ensure that students will not become liabilities for their future employers by ensuring that they have received awareness training on how discrimination law applies in all workplaces. After all, discrimination law extends throughout the European Union and exists in other jurisdictions too such as the United States, Australia, New Zealand.

In addition, it is recommended that in order to give effect to equality and diversity laws in practice, every local authority should offer reasonably priced or free regular access to discrimination and harassment courses to owners and employees of micro and small businesses. Universities should consider whether they could provide partnership in the development and provision of such training.

In both Spain and the UK, it is agreed that training with the objective of awareness raising is a key step to changing and improving workplace cultures. The importance of creating an appropriate workplace culture from the commencement of opening of a new workplace cannot be overstated. Workplace culture depends on workplace standards which depend on workplace values. These need to be agreed by management and conveyed to all new employees who enter an organisation as part of their induction training.

Spanish law already also imposes an obligation on businesses to promote conditions at work that avoid sexual harassment and sex harassment, and states that there should be specific procedures to prevent harassment and to address complaints from anyone who has been the subject of harassment. ${ }^{48}$ Further if an employer has failed to comply with an obligation to develop an equal opportunities policy this is considered a "serious

\footnotetext{
46 Spanish Ministry of Economy, Industry and Competitivity, SMEs Figures, January 2018. http://www.ipyme.org/es-ES/ApWeb/EstadisticasPYME/Documents/CifrasPYME-enero2018.pdf

${ }^{47}$ As reported by the BBC on 1 May 2018 "Exeter university students expelled over racist comments." https://www.bbc.com/news/uk-england-devon-43966504

48 Art. 48 of the Organic Law 3/2007, of 22 March. Organic Law for the effective equality of men and women (hereinafter referred to as "LO 3/2007").
} 
breach" of labour law, but not all employers are under an express obligation to develop an equal opportunities plan. ${ }^{49}$

It is worth considering whether the law should go further and impose an express obligation on employers to provide annual or bi-annual sexual harassment training (and arguably equality and diversity training more generally), with a breach of any such obligation being expressly subject to fines in the Spanish legislation which regulates breaches and fines in employment law regardless of whether or not any sexual harassment complaints have been made. Understanding sexual harassment and providing training on the prevention of sexual harassment is key to creating a conducive work environment based on mutual respect and professionalism for all employees.

The EHRC noted in its report that "including information on sexual harassment in induction is an effective way of ensuring that all new staff are clear about the behaviours expected in the workplace and how to report instances where behaviour falls below this standard. However, only around two out of five employers included such information in their induction processes. Fewer than a third of the employers who provided us with evidence evaluated the effectiveness of their harassment policy through methods such as regular staff surveys." 50

Training needs to be, of course, adapted to the audience, and the contents of the reports provide an interesting view of current workplace attitudes and cultures and as well as the roles of different stakeholders. It is important to ensure that appropriate training is given in the right place, at the right time and in the right way. It is not the same to ask employees, for example, to watch a podcast or short video as to actively engage them in face to face training. The contents of the reports contain observations which are helpful when considering what the contents of quality training may include, and how training may be adapted for different groups within the workplace.

\subsection{Training for senior managers on sexual harassment.}

Senior managers were singled out for their lack of awareness about the extent of sexual harassment in their organisations. ${ }^{51}$ The WEC thought that this "lack of awareness is in part arguably a symptom of the long-standing underrepresentation of women in leadership positions. People did not want to think that this was happening in their organisation; they could not believe that it was happening in their organisation." 52 The EHRC noted that:

A common theme among individuals who reported sexual harassment was a feeling that their employer did not take them seriously, dismissing the reported case as merely 'a bit of fun' or 'laughing it off as boys being boys'. In a number of these cases, it was clear that other people had complained about the same person previously and that the perpetrator's actions were widely known. One respondent said her line manager told her: 'Well you know how he is, just stay out of his way.' This example mirrors other

\footnotetext{
${ }^{49}$ Article 7(13) of LISOS.

${ }^{50}$ Page 10 of the ECHR report.

${ }^{51}$ Paragraph 18 of the WEC report.

${ }^{52}$ Ibid.
} 
responses, which described situations where harassment was tacitly accepted, with the onus put on the person who had been harassed to avoid contact with the perpetrator; often difficult in a work situation. ${ }^{53}$

In giving evidence to the WEC, Kathryn Nawroycki described how organisations can close ranks to protect senior managers when they are accused of sexual harassment:

Quite often, harassment is perpetrated by a senior person to a more junior person. It is very difficult to challenge up the hierarchy in an organisation. [...] It is very typical that organisations will close ranks and protect their more powerful, senior people, even if they know they have crossed a line. It does not take long for that to become very common knowledge amongst employees: that, quite frankly, the organisation would rather keep them there being successful, earning money and doing whatever else, and make that slightly awkward, complaining, more junior person over there go away. ${ }^{54}$

Several studies have found that perpetrators of sexual harassment tend to be in a position of power over the target of the harassment. ${ }^{55}$ This power imbalance needs to be acknowledged and understood. According to TUC report, four out of five women did not report sexual harassment to their employer. ${ }^{56}$ Retaliation fears, concerns over lack of evidence and feelings of shame are some of the frequent reasons given for not reporting concerns. ${ }^{57}$

Another key area which senior management (in order that they can ensure all line managers are appropriately trained), is the prevention of victimisation once a sexual harassment allegation has been made. Sue Coe, Principal for Work and Employment at the EHRC, described much of the practice that the EHRC earned about as "just paperbased compliance." She gave evidence that you could "count on the fingers of one hand the number of organisations that had rounded practice where they had taken steps to train, evaluate that training, include steps in induction, track those who had raised complaints to make sure that they were not being victimised and were not blocked in their progression in the organisation." ${ }^{, 58}$

\subsection{Training for human resources ("HR") professionals.}

According to the EHRC, most people who said they had reported sexual harassment found that the response they received from managers and HR staff was "very unhelpful." 59 In order for HR professionals to carry out their duties effectively it is

\footnotetext{
${ }^{53}$ Page 6 of the EHRC report.

${ }^{54}$ Paragraph 75 of the WEC report.

${ }^{55}$ Page 9 of the TUC report citing Wilson, F. and Thompson, P. "Sexual Harassment as an Exercise Of Power" Gender Work and Organization 8 (1): 61-83, and Gruber, J. and Smith, M. In the Company of Men: Male.

Dominance and Sexual Harassment Northeastern University Press, Boston (2005).

${ }^{56}$ Page 5 of the TUC report.

57 Daurka, K., "Sexual harassment: why we need a mandatory duty and inferences of fact", January/February 2018, Employment Lawyers Association Briefing.

${ }^{58}$ Paragraph 20 of the WEC report.

${ }^{59}$ Page 7 of the ECHR report.
} 
essential that they perceived to be neutral and objective working for the good of the organisation as a whole as opposed to any one individual. The EHRC report notes that:

Another common theme in responses was the existence of a power imbalance between the perpetrator of the sexual harassment and the person being harassed. Many individuals believed that senior colleagues, due to their position of influence within organisations, were not challenged by HR departments or other colleagues, with some describing these individuals as 'untouchable, ${ }^{60}$

In another example, one individual was advised against reporting an incident because it would "damage her brand." 61

HR professionals are often in a difficult position in so far as their role involves balancing conflicting demands between management and employees. One HR professional who submitted evidence to the WEC stated:

There is frequently a stronger drive to maintain the status quo than to deal with the harassing behaviour. Reporters of harassment can be seen as troublemakers or liars, and all too often find themselves unemployed after reporting these incidents. ${ }^{62}$

Consequently, in evidence to the WEC some described how victims lose confidence when they see "other cases being mishandled or dismissed or met with hostility, intimidation or further victimisation." training which recognises that in practice there can be inherent conflicts in their role and which empowers them to challenge the power dynamic which exists in sexual harassment cases. They also need to have the support of the senior management team who understand that in carrying out their duties HR professionals may, at times, uncover awkward and unpalatable truths about individuals who hold positions of influence within the organisation.

HR professionals have a special role to play in ensuring that workplaces are free from harassment. It usually falls within their remit to ensure that there are clear policies outlining the steps to follow if someone is being sexually harassed. They should be instrumental in setting the expected standards of behaviour and the responsibilities of managers. They are also often responsible for providing or procuring sexual harassment training which includes examples of the sorts of behaviour they wish to target. They should be ensuring policies are communicated on an ongoing basis, for example, through antiharassment weeks, training or posters. They should also be regularly monitoring the effectiveness of policies through staff surveys. In practice, the EHRC noted that "fewer than a third of the employers who provided us with evidence evaluated the effectiveness of their harassment policy through methods such as regular staff surveys. ${ }^{\prime 64}$

\footnotetext{
${ }^{60}$ Page 5 of the ECHR report.

${ }^{61}$ Page 5 of the ECHR report.

${ }^{62}$ Paragraph 71 of the WEC report.

${ }^{63}$ Paragraph 71 of the WEC report.

${ }^{64}$ Page 10 of the ECHR report.
} 


\subsection{Sexual harassment and awareness training for trade union and employee representatives.}

In the UK, according to the TUC report, only one per cent of those women who had experienced sexual harassment confided in their trade union representative. ${ }^{65}$ There is clearly therefore a role for trade unions to play in increasing their visibility in terms of campaigning on behalf of its members for workplaces free from sexual harassment and providing support to victims of sexual harassment. Trade union representatives who work in sectors with seasonal employment and where there is a large female workforce have particular responsibilities in ensuring businesses within these sectors are alert to the additional risks faced by females.

There is in Spain a specific requirement that employee representatives contribute to the prevention of sexual harassment and sex harassment through codes of good practice, raising awareness and training about the sorts of behaviour or conduct that can amount to harassment. ${ }^{66}$ Trade unions can be part of the solution in terms of developing effective sexual harassment prevention training programmes and ensuring that this training is regularly provided to all members of staff.

\subsection{Sexual harassment and awareness training specifically for male colleagues?}

Research in the UK indicates that in in 9 out of 10 cases, the perpetrator of sexual harassment was a man. ${ }^{67}$ According to European Commission research on sexual harassment in the workplace, women working in male-dominated workplaces are more likely to experience sexual harassment. ${ }^{68}$ In light of these findings, it is clear that the issue of sexual harassment in the workplace cannot be resolved without the assistance of men. It is therefore worth reflecting whether some harassment and awareness training should be specifically tailored for male colleagues and provided to male only groups?

This is because men who have not had the benefit of any sexual harassment training often do not realise that sexual harassment in the workplace can occur whether or not the perpetrator meant to harass the victim. They do not realise that sexual harassment can occur unintentionally, or in circumstances where the perpetrators are unaware of the level of upset and offence caused by their behaviour.

It seems that some of the backlash to the \#MeToo movement and Everyday Sexism movement is because expectations in terms of standards of acceptable behaviour for men has not always been defined, explained or managed in the past. For example, there may be a lack of awareness of where the line is between "perceived flirting" and "perceived harassment."

In addition, men, as well as women have a role to play when they are "bystanders" to incidents of sexual harassment. As Dr Rachel Fenton, a researcher into bystander intervention, explained to the WEC, "the environment in which [the harassment]

\footnotetext{
${ }^{65}$ Page 3 of the TUC report.

${ }^{66}$ Art 48.2 LO 3/2007.

${ }^{67}$ Page 15 of the TUC report.

${ }^{68}$ Page 10 of the TUC report citing a report by the European Commission (1999) Sexual Harassment at the Workplace in the European Union.
} 
happens is really important, in terms of what other people's reactions are [...], how supportive they are of what you are suggesting and how other people around you act and respond. If you are met by a sea of silence and nobody shows any kind of solidarity, it reinforces that reporting is not the right thing to do." ${ }^{, 69}$

The fact that men are less likely to experience sexual harassment may exacerbate feelings of shame or embarrassment when it does happen. Specific sexual harassment training for men should include an express acknowledgement of the cultural barriers which may exist for men in terms of reporting sexual harassment.

\subsection{Harassment training and awareness training specifically for female colleagues?}

The WEC report expressly states:

We are concerned by the evidence that many people, particularly women, feel that behaviours that could constitute sexual harassment are so normalised and commonplace that they should just put up with them. This feeling is reinforced when colleagues and others-'bystanders'-see the behaviour but do not step in to support the victim or challenge the perpetrator. A particular issue for both victims and bystanders can be knowing how to challenge unwanted or offensive behaviours in the moment, particularly if they fear being victimised or left unsupported as a result. ${ }^{70}$

Interestingly, the WEC report explains that surveys that ask about experience of "sexual harassment", as opposed to listing examples of specific unwanted behaviours, tend to record a lower positive response from respondents, perhaps because people may not fully understand what type of conduct can fall into the category of "sexual harassment." 71 By the end of any training session on sexual harassment, employees should understand that sexual harassment does not just cover criminal behaviours, but a whole range of lower "micro aggressive" behaviours which have the effect of undermining and belittling victims in the workplace.

One interesting aspect emerging from the conversation amongst women which has surfaced post the \#MeToo movement is how different women react and deal with sexual harassment when confronted with it in the workplace. Anecdotal evidence gauged in general conversation suggests that the most assertive women have been able to successfully confront the perpetrators in a robust way. However other women who may be less assertive by nature and who have never attended any assertiveness training courses may find it more difficult because they fear confrontation. It may be helpful for women to be able to have the conversation within the context of a training session about how to share tips and tactics for confronting uncomfortable situations and having difficult conversations in the workplace. It may also be useful for more assertive women to listen to and understand why less assertive women may feel unable to deal with difficult situations in the same way as themselves. Ideally, women should support and learn from each other, rather than judge each other.

\footnotetext{
${ }^{69}$ Paragraph 47 of the WEC report.

${ }^{70}$ Ibid.

${ }^{71}$ Paragraph 9 of the WEC report.
} 


\section{The role of regulators and professional associations/organisations in ensuring that leaders are equipped to lead on sexual harassment.}

Regulators and professional associations also have a part to play in ensuring that leaders in their industry are conscious of and equipped to deal with their obligations under discrimination law. In its report the WEC has concluded:

Regulators must make it clear that sexual harassment by regulated persons is a breach of regulatory requirements by the individual and their organisation, that such breaches must be reported to the appropriate regulator, and that such breaches must be taken into account when considering the fitness and propriety (or equivalent) of regulated individuals and their employers. Perpetration of or failure to address sexual harassment in the workplace must be recognised as grounds for failing a 'fit and proper person' test or having professional credentials removed. Regulators should also set out the sanctions for perpetrators of sexual harassment in their sectors. ${ }^{72}$

The main regulators of the legal profession are the Solicitors Regulation Authority (SRA) and the Bar Standards Board (BSB). There has traditionally been a gender divide within the legal profession, for example, with partners and decision makers more likely to be male. ${ }^{73}$ Against this background, the Law Society of Scotland, has carried out anonymous surveys which specifically ask members about their experience of sexual harassment in the workplace. ${ }^{74}$ The Law Society of Scotland has acknowledged that "some members (particularly although not exclusively female) have been subjected to a spectrum of inappropriate behaviour." such as physical touching or requesting sexual favours are "less common and do exist." 76 One way in which the Law Society could encourage law firms to think about and address the issue of sexual harassment is to make it obligatory for an element of the annual continued professional development training to be dedicated to equality and diversity training each year.

\section{The role of lawyers in drafting non-disclosure or confidentiality agreements.}

A final issue and a separate issue for the legal profession which has been recently discussed in the UK is the use of unethical non-disclosure or confidentiality agreements (hereinafter jointly referred to as "NDAs). For example, in one well-publicised case, an employee who signed a non-disclosure agreement was not allowed a copy of it and was permitted only to view it where it was held at a law firm's office. In another incident, it was reported that non-disclosure agreements were handed out to young, female waitresses for signing before they served dinner.,"77

\footnotetext{
${ }^{72}$ Paragraph 62 of the WEC report.

${ }^{73}$ See the website of the Solicitors Regulation Authority: How diverse are law firms? http://www.sra.org.uk/solicitors/diversity-toolkit/diverse-law-firms.page

${ }^{74}$ Written submission by the Law Society of Scotland into the Sexual Harassment in the Workplace Inquiry, March 2018. https:/www.lawscot.org.uk/media/359825/emp-sexual-harassment-in-theworkplace.pdf

${ }_{75}^{75}$ Marrs R, February 2018, “Time to call out harassment”, The Journal of the Law Society of Scotland.

${ }^{76}$ Ibid.

${ }^{77}$ As reported in paragraph 112 of the WEC report.
} 
The WEC report noted that such agreements are "used unfairly by some employers and also some members of the legal profession to silence victims of sexual harassment."78 There "is insufficient oversight and regulation of their use." The WEC concluded that:

It is unacceptable that some NDAs are used to prevent or dissuade victims from reporting sexual harassment to the police, regulators or other appropriate bodies or individuals. Those who use NDAs unethically in this way must face strong and appropriate sanctions. ${ }^{79}$

The WEC has proposed that "use of provisions in confidentiality agreements that can reasonably be regarded as potentially unenforceable should be clearly understood to be a professional disciplinary offence for lawyers advising on such agreements." 80

In the meantime, in March 2018, the Solicitors Regulation Authority of England and Wales ("SRA") published a warning notice to solicitors which states that, "while NDAs can be legitimate, they must not prevent anyone from notifying the SRA, or other regulators or law enforcement agencies, of conduct which might otherwise be reportable." 81

\section{Conclusions.}

The truth is that sexual harassment is an uncomfortable subject for people to engage with which is perhaps why it has largely remained "invisible." If this issue is to be tackled it is important that we make it "officially" more visible by collecting official data and recording allegations of sexual harassment.

Employees are employed to perform roles, and people do not necessarily see the prevention of sexual harassment as falling within the remit of their specific role. Most people do not want to think of themselves or their peers as sexual harassers or potential harassers. When people think of sexual harassment, they tend to think of the most serious form which is akin to criminal conduct. There is a general lack of awareness about the insidious effect of working in workplaces which tolerate "jokes" and "comments" of a sexual nature. Not enough is understood about the belittling and demotivating effect these types of behaviours can have on staff who, due to power imbalances, may opt to remain silent.

Sexual harassment exists, it has always existed, but we must do better for ourselves and our sons and daughters as they enter the workforce. We need to take a more proactive approach to preventative training. Universities and education providers should have a formal role to play in preparing the future employees of the workforce by ensuring they understand harassment and discrimination laws, and that they are not potential liabilities for future employers.

\footnotetext{
${ }^{78}$ Page 3 of the WEC report.

${ }^{79}$ Page 3 of the WEC report.

${ }^{80}$ Paragraph 134 of the WEC report.

${ }^{81}$ Warning Notice: Use of non-disclosure agreements (NDAs) issued on 12 March 2018 by the Solicitors Regulation Authority. https:/www.sra.org.uk/solicitors/code-of-conduct/guidance/warning-notices/Useof-non-disclosure-agreements-(NDAs)--Warning-notice.page
} 
Breach of discrimination laws is a business problem because it can result in unhappy employees, financial penalties, and bad publicity for the business. Regulators too, must try to ensure that future leaders are "fit to lead" and attending and providing regular training. Lawyers should also not be complicit in creating an environment in which sexual harassment can thrive by providing non-disclosure or confidentiality agreements with the intention of discouraging people from taking advice about their rights.

The time has come to amend the law to expressly state that all employers have an obligation to ensure staff attend annual or bi-annual training on the issue of sexual harassment. This issue should be given the same priority as we give to training on data protection and money laundering issues. Sanctions for breaches should be imposed, taking into account the size of the business.

Training needs to be quality face to face training which is designed and adapted to make it useful and effective for different audiences. Senior managers need to work as part of a team with HR professionals and line-managers to create a zero-tolerance environment. Trade union representatives in sectors which have more casual employment, and which tend to engage more women have a special role to play to ensure that businesses in these sectors are providing awareness training in order to address the attitudes and behaviours that can permit sexual harassment to thrive. Businesses and organisations can no longer afford to carry on as before, relying on the fear of employees to not speak out. In the $21^{\text {st }}$ century, we can do better, we must do better!

\section{Bibliography.}

-BODELÓN GONZÁLEZ, M.E. y GALA DURÁN, C. (2014), “Teoría y Práctica de los Protocolos frente al acoso sexual”, Revista Española de Derecho del Trabajo no 162.

-CABEZA PEREIRO, J. y NUÑEZ-CORTÉS CONTRERAS, P. (2018), "El Derecho a la Protección Frente Al Acoso Sexual y Sexista en la Relación Laboral”, en LOUSADA AROCHENA, J.F. (Coord.), Curso de Igualdad y Diversidad en las Relaciones Laborales, Tirant lo Blanch.

-CLEARLY, C.; DAWSON, C. AND DEE, M. (July 2018), “Sexual harassment: key issues", Employment Lawyers Association Briefing.

-DAURKA, K. (January/February 2018), "Sexual harassment: why we need a mandatory duty and inferences of fact", Employment Lawyers Association Briefing.

-DAURKA, K. (March 2018), "Kiran Daurka responds to Stephen Levinson", Employment Lawyers Association Briefing.

-Equality and Human Rights Commission in the UK (March 2018), Turning the tables: ending sexual harassment at work.

-European Parliament's Committee on Women's Rights and Gender Equality and commissioned, overseen and published by the Policy Department for Citizen's Rights 
and Constitutional Affairs (March 2018), Bulling and sexual harassment at the workplace, in public spaces and political life in the EU.

-House of Commons: Women and Equalities Committee (2018), Sexual harassment in the workplace report.

-LEVINSON, S. (March 2018), "Sexual harassment: the debate continues", Employment Lawyers Association Briefing.

-MARRS, R. (February 2018), "Time to call out harassment", Journal of the Law Society of Scotland.

-PROCHASKA, E. AND SMITH, M. (July 2018), “Turning the Tables on Sexual Harassment," Employment Lawyers Association Briefing.

-SÁNCHEZ PÉREZ, J. (2015), "El acoso sexual y su proyección en las relaciones laborales", Revista de Información Laboral nº 8.

-Trades Union Congress, 2016, Still just a bit of banter: sexual harassment in the workplace in 2016. 